\title{
Um panorama sobre a Historiografia Islâmica na Idade Média: um diálogo necessário
}

\author{
Elaine Cristina Senko ${ }^{1}$
}

Resumo: Neste artigo temos a intenção de demonstrar um panorama sobre a historiografia islâmica na Idade Média. Destarte, a escrita da História no Islã possui duas divisões primordiais, a época formativa e a época clássica. Acreditamos ser inovadora essa nossa explanação, pois a escrita da História no medievo latino também foi feita por meio dos diálogos e interações com as outras religiões, como em nosso caso a islâmica. Dessa forma, nosso trabalho busca esclarecer mais uma vertente de inteligibilidade do sentido de História na Idade Média.

Palavras-chave: historiografia islâmica; medievo islâmico; islã da época formativa; islã clássico; historiadores islâmicos.

Para pesquisar sobre a historiografia islâmica consultamos a opinião de Ibn Khaldun descrita em sua Muqaddimah sobre alguns historiadores aos quais ele teve acesso ${ }^{2}$, a importante obra de Chase F. Robinson Islamic Historiography ${ }^{3}$, o esclarecedor artigo de Diego Melo Carrasco Una aproximación al mundo de Ibn Jaldún: Precursor

\footnotetext{
${ }^{1}$ Doutora em História UFPR.

${ }^{2}$ KHALDUN, Ibn. Muqaddimah - Os Prolegômenos (tomo I). Tradução integral e direta da língua árabe para a portuguesa por José Khoury e Angelina Bierrenbach Khoury. São Paulo: Instituto Brasileiro de Filosofia, 1958, p. 6-11.

${ }^{3}$ ROBINSON, Chase F. Islamic Historiography. Londres: Cambridge University Press, 2003.
} 
medieval de la Historia de las civilizaciones ${ }^{4}$, a enciclopédia Medieval Islamic Civilization ${ }^{5}$ e fontes islâmicas que se mostraram muito elucidativas. Apresentaremos neste artigo duas etapas da produção da História no Islã: a época formativa e a época clássica.

De uma história oral fomentada pela literatura pré-islâmica e pelas recitações do Alcorão passou-se a uma história escrita (tarij); esta foi a época formativa da História no Islã. Essa transformação ocorreu a partir da organização dos governos islâmicos logo após a morte do Profeta Muhammad, em 632, e a formação do governo dos primeiros califas (rashiduns), visando regular suas leis e também por uma necessidade propedêutica: guardar as palavras do Alcorão e ensinar melhor as palavras do Livro Sagrado. Nesse sentido se desenvolveu ainda mais a produção das ahadiths (histórias sobre os costumes e ações do Profeta Muhammad (c. 570-632), comprovadas como autênticas pela tradição formada por uma cadeia de transmissores de moral íntegra, a isnad), das siras (histórias não comprovadas totalmente pela tradição), dos relatos (ajbar) baseados em vestígios (atar) e o surgimento das primeiras biografias do Profeta Muhammad e das escritas genealógicas.

\footnotetext{
${ }^{4}$ MELO CARRASCO, Diego. Una aproximación al mundo de Ibn Jaldún: Precursor medieval de la Historia de las civilizaciones. In: MARTOS QUESADA, Juan; GARROT GARROT, José Luis. Miradas españolas sobre Ibn Jaldún. 2008. p. 138139.

${ }^{5}$ MERI, Josef W. (Ed.). Medieval Islamic Civilization - an Encyclopedia. New York/London: Routledge, 2006.
} 
Assim havia uma tradição de escrita biográfica, sendo a mais antiga a obra elaborada pelo medinense Muhammad Ibn Ishac (704767) sobre o Profeta Muhammad: Kitab al-Maghazi (Livro das Campanhas Militares do Profeta). O que hoje conhecemos desta escrita de Ibn Ishac é através da obra feita pelo sunita Abd al-Malik Ibn Hisham (m. c. 833) Al-Sira al-Nabawiyya (A Vida do Profeta) e que esta iniciou o gênero narrativo Sira. Ibn Hisham consultou o registro de um dos discípulos de Ibn Ishaq, al-Bakka'i (m. 799). Ibn Hisham alterou a estrutura original da obra de Ibn Ishac, pois na nova versão o autor reduziu o tamanho do trabalho, deixou de fora a história bíblica de Adão a Abraão e a descendência de Ismael até Muhammad e alguns poemas livres. O trabalho original de Ibn Ishac era dividido em três partes: 1. do período pré-islâmico perpassando o advento de Jesus e chegando até o período inicial da vida de Muhammad em Meca; 2. das atividades de Muhammad em Meca; 3. acerca das campanhas militares em Medina. Segundo Claude Gilliot, a obra de Ibn Ishac foi divulgada não de uma só vez, mas dividida em partes, e por isso sua obra foi reunida posteriormente ${ }^{6}$. Essa intenção educativa religiosa permaneceu entre os omayas de Damasco e aprimorou-se com a dinastia abássida.

Ainda no período formativo citemos o historiador sunita de Kufa, Ibn Al-Kalbi (m. 821) e suas obras Livro das Genealogias e o

${ }^{6}$ GILLIOT, Claude. Ibn Ishaq. MERI, Josef W. (Ed.). Medieval Islamic Civilization - an Encyclopedia. New York/London: Routledge, 2006, p. 357-358. 
Kitab Al-Asnam (Livro dos ídolos) ${ }^{7}$. As iniciais crônicas começavam suas narrativas com a Criação, relatam os tempos pré-islâmicos, chegam até o advento do islamismo e continuam relatando sobre os homens de poder de uma determinada dinastia. Ou seja, as primeiras crônicas começaram com a pretensão de uma história universal e terminam por se limitar, geralmente, a recolher informações de uma determinada época ou dinastia. Também o cádi sunita de Bagdá Muhammad Ibn Omar Al-Uáqidi (747-823), por exemplo, compôs uma escrita sobre as conquistas islâmicas desde o surgimento da instituição do califado, assim esboçando uma narrativa cronística resultando na obra Kitab alTarikh wa'l Maghazi (Livro da História e Batalhas). Já Saif Ibn Omar Al-Açadi, no século IX, citado muitas vezes pelo historiador Al-Tabari, compôs uma obra sobre a conquista dos primeiros muçulmanos, uma outra obra intitulada História das Revoltas e Apostasias e mais uma obra, História da Batalha do Camelo ${ }^{8}$. Ao mesmo tempo, no Egito, o historiador sunita Ibn Al-Hakam (798-871) produzia também a história de um acontecimento: História da conquista de Al-Andaluz ${ }^{9}$. Al-Hakam

7 Conferir em http://www.answering-islam.org/Books/Al-Kalbi/ (Acesso em 22/07/2011). Lembremos que muitos dos escritos de Ibn Al-Kalbi estão presentes no Kitab Al-Agani.

${ }^{8}$ Nota 11 dos tradutores José Khoury e Angelina B. Khoury em: KHALDUN, Ibn. Muqaddimah - Os Prolegômenos (tomo I). Tradução integral e direta da língua árabe para a portuguesa por José Khoury e Angelina Bierrenbach Khoury. São Paulo: Instituto Brasileiro de Filosofia, 1958, p. 7.

${ }^{9}$ AL-HAKAM, Ibn. History of the conquest of Spain. Tradução da língua árabe por John Harris Jones (edição bilíngüe). London: Williams \& Norgate, 1858. O referido 
desejava buscar os fatos militares e políticos partindo da particularidade para alcançar um aspecto mais abrangente do evento narrado. Já no ambiente andaluz, destacamos o historiador omaya Ibn Hayan (9871076) como um dos exemplos de cronistas de dinastias com suas obras Moctabas fi Tarikh al-Andalus e mais uma crônica chamada Matín ${ }^{10}$.

As mais conhecidas crônicas do Islã da época formativa são de autoria de Al-Tabari (839-923), historiador de origem persa, que muito cedo, com sete anos de idade, já aprendera as lições corânicas; quando adulto, por volta de 856, ficou em Bagdá por dois anos fazendo novos estudos na Casa da Sabedoria, e depois de muito tempo, já em 870, retorna a esse local como mestre. As especialidades temáticas do historiador Al-Tabari eram: teologia, história e comentários corânicos. As duas obras mais conhecidas de Al-Tabari são: História dos Profetas $e$ dos Reis e a obra Comentário sobre o Alcorão (Tafsir) ${ }^{11}$. Nessa mesma época, o historiador Al-Yaqubi (m. 971) tinha a pretensão de organizar de modo objetivo as tradições e os fatos escritos pelos antigos escritores islâmicos.

historiador obteve tal documento através da transcrição feita por seu Professor Ewald em 1829.

${ }^{10}$ Nota 14 dos tradutores José Khoury e Angelina B. Khoury em: KHALDUN, Ibn. Muqaddimah - Os Prolegômenos (tomo I). Tradução integral e direta da língua árabe para a portuguesa por José Khoury e Angelina Bierrenbach Khoury. São Paulo: Instituto Brasileiro de Filosofia, 1958, p. 9.

11 JUDD, Steven C. Al-Tabari. In: MERI, Josef W. (Ed.). Medieval Islamic Civilization - an Encyclopedia. op. cit., 2006, p. 791-792. 
Um modelo de escrita sob a forma de recolhimento de dados que mistura o inicial modelo de escrita cronística com a genealogia e a biografia é a produção de Ibn Al-Nadim (m. 998) em seu Al-Fihrist (Index). Neste livro Al-Nadim recolheu toda uma bibliografia islâmica anterior ao século $\mathrm{X}$, tendo em vista que muitas obras estavam sendo destruídas pelo tempo e pela alteração dos copistas. Neste trabalho, que possui dez capítulos, é interessante observar as temáticas escolhidas e empregadas: as lições corânicas; a gramática da linguagem árabe; a genealogia dos escritores anteriores ao autor, incluindo historiadores; os poetas e suas poesias do período pré-islâmico; os homens de poder das dinastias dos omayas (661-750) e dos abássidas (750-); as teologias islâmicas (a cética e a mística); aspectos da jurisprudência; considerações sobre o conhecimento advindo das leituras e traduções dos clássicos da Antiguidade; as formas de arte (contadores de estórias, atores de rua e mágicos); sobre os povos de sua época não islâmicos e, ao final da obra, um estudo sobre a Alquimia. Essa descrição geral dos capítulos demonstra a organização da escrita do modelo de Bagdá, local de florescimento de uma nova e pujante intelectualidade.

Por volta desse século X conhecemos a época clássica da escrita da História no Islã, em que se aperfeiçoam as biografias, se instiga uma busca pela ordem cronológica e se rastreiam as dinastias 
dos poderosos ${ }^{12}$. No entanto, sabemos que os historiadores islâmicos não se especializavam em um tipo apenas de gênero e sim escreviam ao mesmo tempo, e às vezes até misturando as três categorias de narrativas referidas. Vamos demonstrar a prevalência de um dos três gêneros em alguns historiadores, mas tendo a consciência da inteligibilidade de todas para o escritor. Nessa segunda etapa ganham espaço as histórias autenticadas fundamentalmente pela isnad.

No Islã os fatos históricos eram entendidos como resultados de leis, estas dirigidas por Allah $^{13}$. Os homens deveriam seguir a esquemática proposta por Deus dentro de um pensamento escatológico providencialista. A escrita da História no Islã do período clássico girava em torno de três categorias: a biografia, a crônica (de caráter universal) e a genealogia (estudos sobre um grupo, no qual se destacam algumas individualidades $)^{14}$. No entanto, além delas havia a preocupação em se estudar a geografia, sobre as escolas jurídicas e filosóficas, acerca da exegese corânica, as regras oriundas da jurisprudência; compreender a burocracia islâmica e a arte da literatura (pré-islâmica e islâmica).

${ }^{12}$ MELO CARRASCO, Diego. Una aproximación al mundo de Ibn Jaldún: Precursor medieval de la Historia de las civilizaciones. In: MARTOS QUESADA, Juan; GARROT GARROT, José Luis. Miradas españolas sobre Ibn Jaldún. op. cit., 2008, p. 138-139.

13 Entendimento de M. Behesti, citado por Diego Melo Carrasco. In: MELO CARRASCO, Diego. Una aproximación al mundo de Ibn Jaldún: Precursor medieval de la Historia de las civilizaciones. In: MARTOS QUESADA, Juan; GARROT GARROT, José Luis. Miradas españolas sobre Ibn Jaldún. Madrid: Ibersaf, 2008, p. 138.

${ }^{14}$ ROBINSON, Chase F. Islamic Historiography. Londres: Cambridge University Press, 2003, p. 55. 
Chase F. Robinson nos chama a atenção para a formação do historiador islâmico, a qual aponta para vários aprendizados simultâneos ${ }^{15}$.

É interessante observar a existência de uma literatura de viagem, Rhila, que compunha um estilo narrativo histórico, representada especialmente, como vimos na citação de Melo Carrasco, pelo andaluz Ibn Yubair (1145-1217) e pelo berbere de Tanger, Ibn Batuta (1304-1377). Ressaltamos que a escrita de estilo autobiográfico tem uma ligação com esses homens que viajam intensamente, como é o caso de Ibn Batuta e Ibn Khaldun: ambos escreveram seus relatos de si e dos caminhos percorridos em vida.

Já o cronista Al-Maçudi (871-956) nasceu em Bagdá e morreu em Fustat, no Egito. Além de historiador, foi viajante e geógrafo, tendo escrito em Basra a obra Muruj adh-dhahab wa ma'ädin al-jawahir (Os prados de ouro e as minas de pedras preciosas). A estrutura da obra de Maçudi, Muruj adh-dhahab wa ma'ädin al-jawahir, inicia-se com um levantamento dos historiadores e cronistas conhecidos pelo autor. Depois ele passa para a narrativa hebraica da criação do mundo e de seus principais governantes, tais como Salomão e David. Nesse ínterim, relata a história da fundação do islamismo com o Profeta Muhammad. Em seguida, Maçudi passa a analisar a história da Índia, a fazer estudos geográficos e climáticos sobre o mar Mediterrâneo, o litoral de Constantinopla e o mar Cáspio. Além disso, Maçudi relata a história de

\footnotetext{
${ }^{15}$ ROBINSON, Chase F. Islamic Historiography. Londres: Cambridge University Press, 2003, p. 59.
} 
vários povos: dos chineses, turcos, sírios, persas, gregos, romanos, bizantinos, egípcios, eslavos, francos, andaluzes, lombardos e dos curdos. Maçudi também faz uma análise sobre as arquiteturas dos indianos, gregos, romanos, eslavos e dos sabeus de Harran. Na continuidade, existe um aprofundamento da biografia do Profeta Muhammad, um levantamento dos califas até a época do próprio Maçudi e sobre suas viagens por Síria, Palestina, Pérsia, Armênia, Mar Cáspio, Índia, Ceilão, Omã, o mar da China, África do Leste até Madagascar. Maçudi também entrou em contato com as religiões judaica, cristã, hindu e zoroastrista. Ele produziu principalmente obras de modelo cronístico enciclopédico e se interessava pela filosofia clássica, a poesia, a controvérsia, o comércio, a navegação e a história natural. Outras obras escritas por Maçudi foram: Akhbar az-zaman (A História do Tempo) e o Kitab at-tanbih wa al-ishraf ( $O$ Livro das Advertências) ${ }^{16}$.

${ }^{16}$ Al-Maçudi tinha consciência da prática histórica que possuía diversas versões: "Um dos recursos dessa prática, fundamental na recolha dos relatos dos hadites do profeta Maomé, era o isnad, que consistia no encadeamento de testemunhos que efetuavam uma regressão temporal linear - 'ouvi de fulano, que ouviu de beltrano, que ouviu de sicrano, que ouviu de alano etc'. Eventualmente, os historiadores muçulmanos utilizam, além do princípio de regressão temporal, o da dispersão geográfica (...). Ao lado disso, outro recurso, mais comum nas obras de adab (decoro), é a citação de fonte escrita precedida da fórmula "li (ou fulano disse ter lido) em certo livro da Pérsia (ou da Î́ndia, ou da Grécia) etc". In: JAROUCHE, Mamede Mustafa. Uma poética em ruínas. op. cit., 2006, p. 17-18. Temos acesso à obra de Al-Maçudi Os prados de ouro e as minas de pedras preciosas: a Société Asiatique publicou de 1861 a 1877 o Murūj adh-dhahab wa ma 'ādin al-jawāhir nas línguas árabe e francesa, sob a coordenação e tradução de Charles Barbier de Meynard (1826-1908) e Abel Pavet de Courteille (1821-1889) os tomos I, II, III. Depois a tradução ficou sob a responsabilidade de 
Em Al-Andaluz temos um exemplo de uma obra de estrutura genealógica mais elaborada: A conquista da Andaluzia, redigida pelo erudito andaluz Ibn Al-Kouthyia (m. 977). O historiador Al-Kouthyia nasceu em Sevilha e também viveu em Córdoba, onde aprendeu muitas de suas lições. Era tataraneto de Witiza (Ghaytacha) por meio da linhagem de Sara, a Goda, filha por sua vez de um dos herdeiros de Witiza, Alamundo. Dessa filiação deriva seu nome, Al-Kouthya, que significa o filho da Goda. Em sua obra acerca da conquista de AlAndaluz $^{17}$, o historiador contempla tal acontecimento de forma breve para se deter, especificamente, na história de sua própria família, buscando assim uma espécie de legitimação para seus antepassados godos e islâmicos por meio da escrita genealógica. O referido historiador Al-Kouthya se interessava muito pela literatura e história política andaluza. Com um estilo mais crítico e menos retórico, o historiador sevilhano tinha um apurado olhar questionador sobre os fatos históricos, detectando neles a variedade de possibilidades interpretativas. Também nos chama a atenção a produção do historiador Ibn Al-Rakik (m. 952), que escreveu uma História de Ifrikya e uma genealogia das tribos berberes no Norte de África.

Charles Barbier de Meunard (tomo IV ao IX). Publicação: MAÇOUDI. Livre des prairies d'or et des mines de pierres précieuses (tomo I-IX). Paris: Société Asiatique, 1861-1877.

17 AL-KOUTHYIA, Ibn. La conquête de L'Andalousie. Tradução francesa de M. Cherbonneau. Paris: Journal Asiatique, 1853. 
Além deles, citamos a produção no estilo cronístico do historiador persa Ibn Miskawayh (932-1030), neo-platonista, que foi influenciado pelos filósofos da falsafa, resultando em sua obra de história Tajarib al-umam (Experiência dos Povos). Dentro desse estilo de narrativa estão os escritos do damasceno Al-Qalanisi (m. 1160): Mudhayyal Ta'rikh Dimashq (Continuação das Crônicas de Damasco $)^{18}$. Inclusive, Al-Qalanisi continuou as crônicas iniciadas anteriormente pelo historiador Hilal Ibn Al-Muhassin Al-Sabi (9691056). Outros historiadores que continuam com essa estrutura de crônicas são o historiador curdo Ibn Al-Athir (1160-1231), o qual conheceu Saladino e escreveu sua obra-prima, Al-Kamil fi Tarikh (Uma História Completa), e Baha al-Din Ibn Shaddad (m. 1235), que escreveu uma narrativa sobre os feitos de Saladino intitulada $\mathrm{Al}$ Nawadir al-Sultaniyya wa'l-Mahasin al-Yusufiyya (Uma Preciosa e Excelente História sobre Saladino). Ao lado desses historiadores se apresentam os sírios Ibn Al-Adim (1192-1262), que escreveu uma História de Alepo, e Ibn Khallikan (1211-1282); este escreveu a seguinte obra: Wafayat al-a'yan wa-anba abna az-zaman (Mortes dos homens eminentes e a História dos filhos de suas épocas), escrita entre 1256 e $1274^{19}$. Já a partir de Ibn Khaldun (1332-1406), com sua obra

\footnotetext{
${ }^{18}$ ROBINSON, Chase F. Islamic Historiography. Londres: Cambridge University Press, 2003, p. 143.

${ }^{19}$ ROBINSON, Chase F. Islamic Historiography. Londres: Cambridge University Press, 2003, p. xv.
} 
Muqaddimah, a escrita da História se apresentou como de espírito crítico e com o retomar do pensamento clássico de busca pela verdade. Entretanto, em seu próprio tempo Ibn Khaldun não obteve muita recepção, mas Al-Maqrizi (1364-1442) foi um de seus discípulos e permitiu à historiografia islâmica um último suspiro ante a reviravolta teológica que viria a seguir.

Portanto, a escrita da História no Islã nos indicou que os estilos de narrativas desenvolvidas giravam em torno da biografia, da genealogia e principalmente do modelo cronístico, agregador das outras duas. Da época formativa para o período clássico esses gêneros se desenvolveram e se misturavam. Entretanto, Ibn Khaldun, no século XIV, chamaria a atenção para o método da busca pela verdade e a um não fazer cronístico simples por parte do historiador, se inspirando muito mais no pensamento clássico, dentro de uma época vivida por ele de desagregação da comunidade islâmica no Ocidente. 


\section{Referências bibliográficas:}

AL-KALBI, Ibn. http://www.answering-islam.org/Books/Al-Kalbi (Acesso em 22/07/2011).

AL-KOUTHYIA, Ibn. La conquête de L'Andalousie. Tradução francesa de M. Cherbonneau. Paris: Journal Asiatique, 1853.

GILLIOT, Claude. Ibn Ishaq. In: MERI, Josef W. (Ed.). Medieval Islamic Civilization - an Encyclopedia. New York/London: Routledge, 2006, p. 357-358.

JAROUCHE, Mamede Mustafa. Uma poética em ruínas. Livro das mil e uma noites, vol. I: ramo sírio/Anônimo. Tradução do árabe para a língua portuguesa por Mamede Mustafa Jarouche. 3 ed. São Paulo: Globo, 2006.

JUDD, Steven C. Al-Tabari. In: MERI, Josef W. (Ed.). Medieval Islamic Civilization - an Encyclopedia. New York/London: Routledge, 2006, p. 791-792.

KHALDUN, Ibn. Muqaddimah - Os Prolegômenos (tomo I, II, III). Tradução integral e direta da língua árabe para a portuguesa por José Khoury e Angelina Bierrenbach Khoury. São Paulo: Instituto Brasileiro de Filosofia, 1958-1960. 
MAÇOUDI. Livre des prairies d'or et des mines de pierres précieuses (tomo I-IX). Paris: Société Asiatique, 1861-1877.

MELO CARRASCO, Diego. Una aproximación al mundo de Ibn Jaldún: Precursor medieval de la Historia de las civilizaciones. In: MARTOS QUESADA, Juan; GARROT GARROT, José Luis. Miradas españolas sobre Ibn Jaldún. Madrid: Ibersaf, 2008. p. 135-146.

ROBINSON, Chase F. Islamic Historiography. Londres: Cambridge University Press, 2003.

Recebido em 21/11/2014, aceito para publicação em 16/05/2016 